\title{
Gas Chromatography Mass Spectrometry Assay for Ketamine and its Metabolites in Plasma
}

\author{
Serrine S. Lau† and Edward F. Domino \\ Department of Pharmacology, The University of Michigan, Ann Arbor, Michigan 48109, U.S.A.
}

\begin{abstract}
A highly sensitive and specific method for quantitation of ketamine and two of its metabolites found in monkey, dog and human plasma was developed using a gas chromatography selected ion monitoring assay operated in both electron impact and chemical ionization modes. This technique yields excellent precision, reproducibility and accuracy. From $1 \mathrm{ng}$ to $3 \mu \mathrm{g}$ of ketamine or its metabolites in $1 \mathrm{ml}$ of plasma can be detected. The technique of electron capture gas chromatography is compared. All three assays were found to be quite useful but the gas chromatography mass spectrometry techniques were more specific.
\end{abstract}

\section{INTRODUCTION}

Earlier studies for the assay of ketamine 2-(o-chlorophenyl)-2-(methylamino)-cyclohexanone $\mathrm{HCl}(\mathbf{1})$ have been carried out with fluorimetry ${ }^{1}$ and gas chromatography. ${ }^{2-4}$ Although the latter technique provides sufficient sensitivity for routine clinical use, undesirable interference sometimes occur, particularly with flame ionization when the size of biological samples is limited or when the drug concentration is very low.

It is our purpose to develop a sensitive, selective and specific method of quantitative analysis of ketamine and its metabolites in plasma, a suitable assay for plasma samples which have widely varying drug levels that could be used in pharmacokinetic studies. A significant increase in sensitivity and specificity of detection using a gas chromatograph mass spectrometry computer system (g.c.m.s. com.) was achieved in the assay reported herein.

\section{EXPERIMENTAL}

\section{Extraction and derivatization}

The extraction and derivatization of ketamine (1) was that of Chang and Glazko. ${ }^{2}$ The flow diagram of the procedure is shown in Fig. 1. CL-394, the $o-\mathrm{Br}$ analog (2) of ketamine, was used as the internal standard. Ketamine, CL-394 and ketamine metabolites were provided generously by Dr A. J. Glazko, Parke, Davis and Co., Ann Arbor, Michigan. Heptafluorobutyric anhydride was obtained in $1 \mathrm{ml}$ ampules or a $25 \mathrm{~g}$ bottle from Pierce Chemical Co., Rockford, Illinois. 'Nanograde' solvents were obtained from Mallinckrodt Chemical Works, St Louis, Missouri. The column packing, 3\% OV-17 on 100/120 Gas Chrom Q, was obtained from

$\dagger$ Predoctoral Fellow, Barbour Scholarship, Rackham School of Graduate Studies.

末 To whom all correspondence should be directed.

(C) Heyden \& Son Ltd, 1977
Applied Science Laboratories, Inc., State College, Pennsylvania.

\section{Analysis}

Quantitative analyses were made on two different instruments. The first was a Finnigan 3200 g.c.m.s. com. system operated in electron impact (e.i.) and chemical ionization (c.i.) modes and the second a HewlettPackard 7610A gas chromatograph equipped with an electron capture detector of $\mathrm{Ni}^{63}$. For the analysis with the Finnigan a $5 \mathrm{ft} \times 2 \mathrm{~mm}$ glass U-tube column packed with $3 \% \mathrm{OV}-17$ on $100 / 120$ mesh on Gas-Chrom Q was conditioned by heating overnight at $250^{\circ} \mathrm{C}$. The g.c. conditions were: column temperature $180^{\circ} \mathrm{C}$ isothermal, injector temperature $210^{\circ} \mathrm{C}$. In g.c.m.s.e.i. the electron energy was 25 or $70 \mathrm{eV}$. The carrier gas flow (He) was $20 \mathrm{ml} \mathrm{min}^{-1}$. The glass jet separator temperature was $210^{\circ} \mathrm{C}$. In g.c.m.s.c.i. the reactant gas methane was run at 380 microns pressure. Electron energy was $70 \mathrm{eV}$. The Hewlett-Packard was equipped with an automatic integrater. Column size was $6 \mathrm{ft} \times 4 \mathrm{~mm}$ Utube glass column packed with $3 \%$ OV-17. Argon+ methane (95:5) gas was used as the carrier gas. The unit was operated isothermally at $175^{\circ} \mathrm{C}$ with the detector maintained at $250^{\circ} \mathrm{C}$.

\section{RESULTS AND DISCUSSION}

The metabolic products of ketamine were first identified in plasma, urine and bile by Glazko and Chang. ${ }^{5,6}$ Both ketamine metabolite 1a and ketamine metabolite $\mathbf{1 b}$ can be detected in small amounts in plasma after ketamine administration. ${ }^{2}$ The structures of the derivatized compounds are shown in Fig. 4. The extraction and derivatization procedure for ketamine and its metabolites from dog, monkey and human plasma provided excellent gas chromatographic separation. Derivatization was necessary since without it both ketamine (1) and CL-394 (2) showed peaks with small shoulders when run in a gas chromatograph with a flame ionization detector. However, after derivatization, sharp and symmetrical peaks 


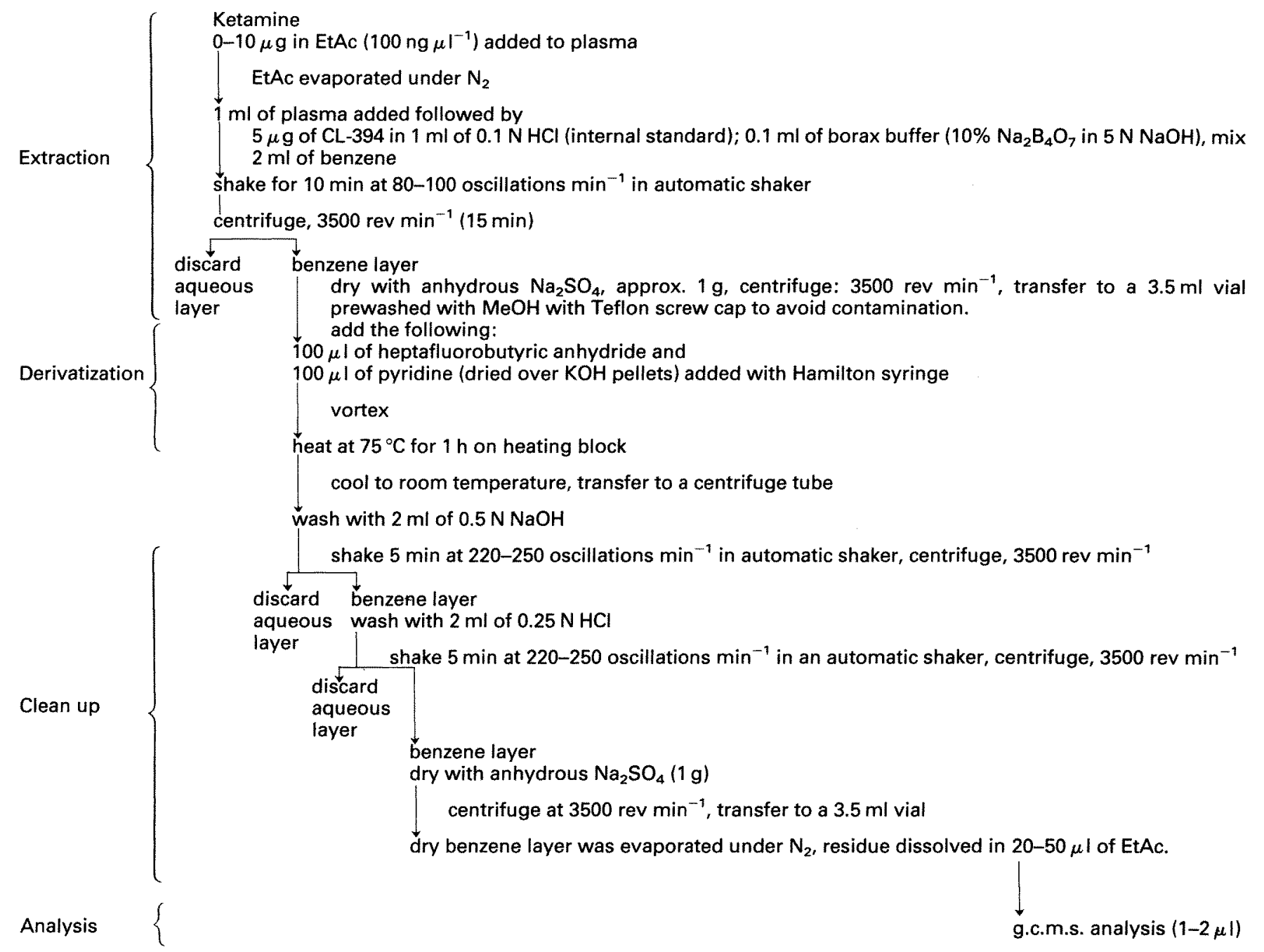

Figure 1. Flow diagram for the extraction and derivatization of ketamine and metabolites in plasma (after Chang and Glazko ${ }^{2}$.

were obtained. Ketamine metabolites $\mathbf{1 a}$ and $\mathbf{1 b}$, which are primary amines, are also extracted and derivatized with the same procedure so all three compounds can be detected in a single plasma sample. A typical total ion chromatogram with approximately $100 \mathrm{ng}$ of $\mathbf{1}, \mathbf{1 a}, \mathbf{1 b}$ and $\mathbf{2}$ extracted from monkey plasma is shown in Fig. 2. Similar chromatograms were obtained with either e.i. (using an electron energy of $25 \mathrm{eV}$ ) or c.i. (using methane at a pressure of 380 microns). The mass spectra of the heptafluorobutyryl derivatives are illustrated in Figs 3 and 4 in both modes. Part of the spectra were multiplied as shown in order to better indicate the small intensity ions. Small molecular ions $[\mathrm{M}]^{+}$as well as the characteristic $\mathrm{Cl}$ and $\mathrm{Br}$ isotope ions $[\mathrm{M}+2]^{ \pm}$were obtained in the e.i. spectra of $\mathbf{1}, \mathbf{2}$ and $\mathbf{1 b}$. No molecular ion was obtained for 1 a but a $m / e 384$ for the fragment $[\mathrm{M}-\mathrm{Cl}]^{+}$was present. The intensity of the molecular ions was reduced when the mass spectrometer was operated at electron energies of $70 \mathrm{eV}$. As might be expected because of their similar structures, 1 and $\mathbf{2}$ show corresponding e.i. spectra. All the quantitative analyses using selected ion monitoring were carried out with the mass spectrometer operated at electron energy of $70 \mathrm{eV}$ since the mass fragments rather than molecular ions were monitored selectively. The fragment $m / e 210$ was the base peak for $\mathbf{1}$ and $\mathbf{2}$. The conjugate double bond in $\mathbf{1 b}$ apparently stabilizes the molecule for very few fragments are seen in its spectrum. Postulated structures of the major fragments are shown in Tables 1 and 2 . Spectra obtained in the c.i. mode using methane as the reactant gas at 380 microns pressure gave the quasimolecular ions $[\mathrm{M}+\mathrm{H}]^{+}$of all four compounds as the base peaks. Other ion species such as $\left[\mathrm{M}+\mathrm{C}_{2} \mathrm{H}_{5}\right]^{+}$ and $\left[\mathrm{M}+\mathrm{C}_{3} \mathrm{H}_{5}\right]^{+}$were also obtained. Characteristic $m / e$ 205,207 and 251 ions corresponded to the loss of the heptafluorobutyryl amine group. For quantitative purposes, selected ion monitoring was used with $m / e 210$ for 1 and 2 and $m / e 102$ for both metabolites under e.i. condition. The quasimolecular ions $[\mathrm{M}+\mathrm{H}]^{+}$of the compounds $(m / e 418,420,434,478)$ or the major fragments $m / e 205,207,251$ were selectively monitored in the c.i. mode.

CL-394 (3 $\mu \mathrm{g})$ (internal standard) was added to monkey plasma $(1 \mathrm{ml})$ containing known amounts of $\mathbf{1}, \mathbf{1 a}$ and $\mathbf{1 b}$ and extracted and derivatized as described in Fig. 1. Aliquots of the (1-2 $\mu \mathrm{l})$ sample were analyzed. Each sample was analysed twice and the two peak area ratios averaged. Standard curves of peak area ratio under e.i. conditions were linear and passed through the origin for all three compounds (Fig. 5). The ratio of fragment $m / e$ $210 / 210$ was used for 1 and $102 / 102$ for both $\mathbf{1 a}$ and $\mathbf{1 b}$. Similar linearity was obtained using c.i., as shown in Fig. 


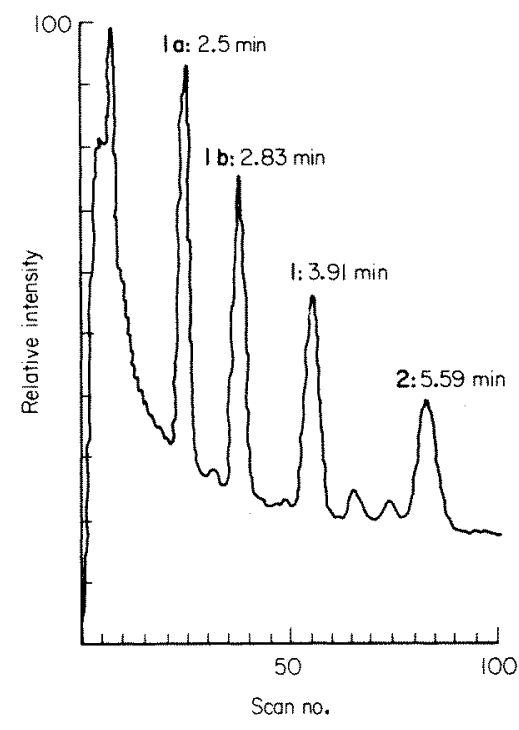

Figure 2. Total ion chromatogram of the heptafluorobutyryl derivatives of ketamine (1), ketamine metabolite 1a, ketamine metabolite 1b and the $0-\mathrm{Br}$ analog (2) of ketamine as internal standard (i.s.). The g.c.m.s. conditions are as follows: column: $3 \%$ OV-17; solution: ethyl acetate; column temp.: $170^{\circ} \mathrm{C}$; separator temp.: $210^{\circ} \mathrm{C}$; helium flow: $20 \mathrm{ml} / \mathrm{min}^{-1}$. A total of $5 \mu \mathrm{g} \mathrm{ml}^{-1}$ of each was added to monkey plasma. The extracted and derivatized products were then injected as $100 \mathrm{ng} \mu \mathrm{l}^{-1}$ of the final extract. Note the minor peaks in the total ion chromatogram which are also present in extracts of control plasma. No interference was noted, however, in the mass fragmentograms.
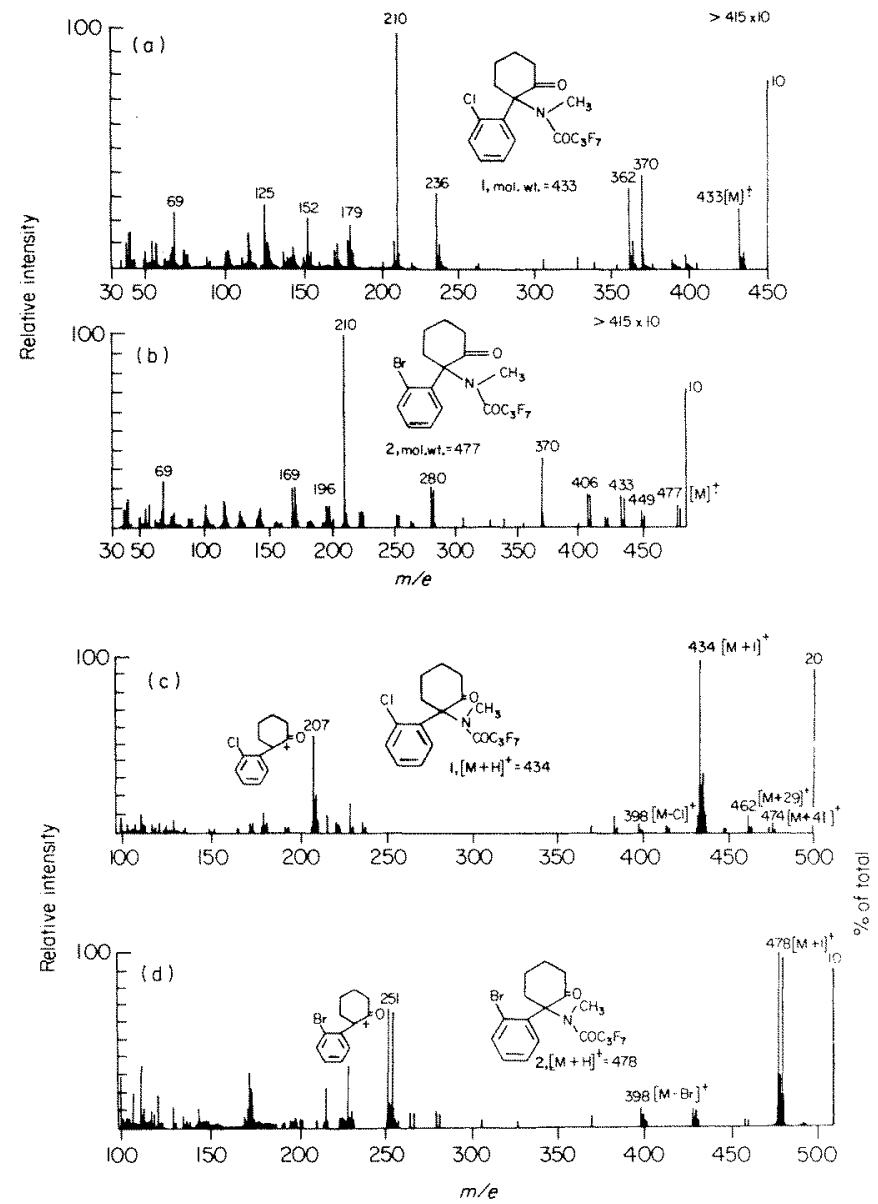

Figure 3. Mass spectra of the heptafluorobutyryl derivatives of ketamine (1) and its $\mathrm{o}-\mathrm{Br}$ analog (2) in e.i. ( $\mathrm{a}$ and $\mathrm{b}$ ) and c.i. (c and d) modes. Operating conditions for data of this and the subsequent figures are given in the text under Analysis.
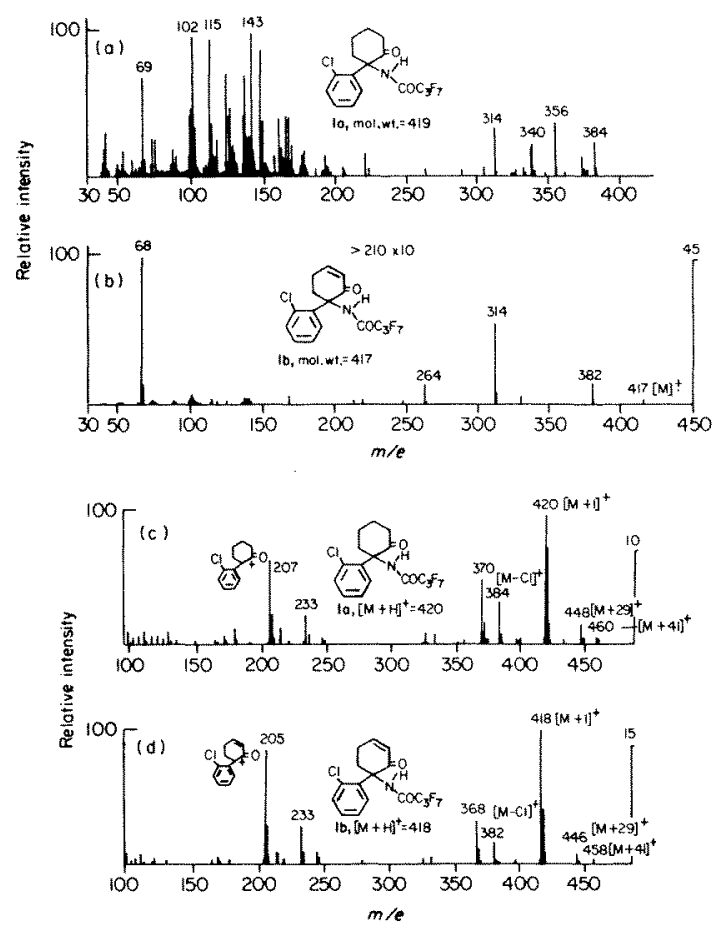

Figure 4. Mass spectra of the heptafluorobutyryl derivatives of ketamine metabolites $1 a$ and $1 b$ in e.i. ( $a$ and $b$ ) and c.i. ( $c$ and d) modes. Conditions are as described in the legend of Fig. 2.

6 . The analysis of ketamine and its two metabolites by selected ion monitoring is shown in Fig. 7. The ions monitored were $m / e 210$ for 1 and 2 and $m / e 102$ for the metabolites. Ions $m / e 356$ and $m / e ~ 314$ for $1 a$ and $\mathbf{1 b}$ were also monitored for identification purposes. The specificity of this technique is exemplified by the lack of contamination in the background spectrum and the presence of characteristic fragment peaks (Figs. 7 and 8 ). Similar results to those found with monkey plasma in both the e.i. and c.i. modes were obtained also from dog and human plasma extractions to which 1, 2, 1a, and $\mathbf{1 b}$ were added in varying amounts.

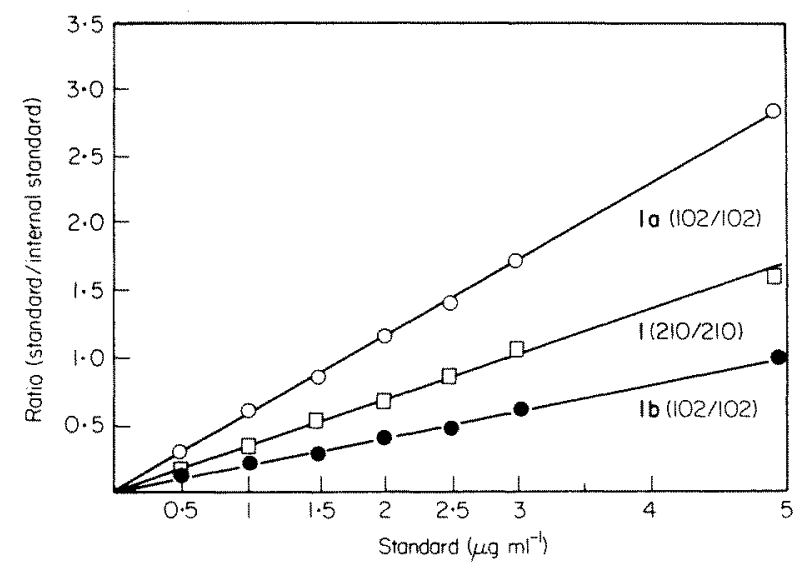

Figure 5. Standard calibration curve for 1, 1a, and $\mathbf{1 b}$ in monkey plasma using electron impact selected ion recording. The internal standard (2) was $3 \mu \mathrm{g} \mathrm{ml}^{-1}$ of plasma, while the ketamine and its metabolites were varied as shown. Of the final extracted volume of $20 \mu \mathrm{l}, 1 \mu \mathrm{l}$ of sample was injected. Hence, the total amount added was $1 / 20$ of the total amounts shown. A total of $25 \mathrm{ng}$ can very easily be detected. About $1 \mathrm{ng}$ is a reasonable limit of sensitivity. 
Table 1. Postulated structures of e.i. mass fragments of ketamine (1) and its $o-\mathrm{Br}$ analog (2)

[M]:

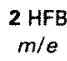

$[\mathrm{M}+2]+$

477

479

$\mathrm{CH}_{3}, \mathrm{COC}_{3} \mathrm{~F}_{7}$

$[\mathrm{M}-28]^{ \pm}(\mathrm{M}-\mathrm{CO})$<smiles>[X]c1ccccc1C(CCCC)N(C)CC</smiles>

449

405<smiles>CCC(=O)OC(=O)OCc1ccccc1</smiles>

$[\mathrm{M}-57]^{+}$

$\left(\mathrm{M}-\mathrm{C}_{3} \mathrm{H}_{5} \mathrm{O}\right)$<smiles>[X]c1ccccc1C(C)(C)N(C)CC</smiles>

420

376<smiles>[X]c1ccccc1C(=C)N(C)C(=O)C(F)(F)F</smiles>

406

$\left(\mathrm{M}-\mathrm{C}_{4} \mathrm{H}_{7} \mathrm{O}\right)$

$[\mathrm{M}-28-\mathrm{X}]^{+}$

$(\mathrm{M}-\mathrm{CO}-\mathrm{Cl})$<smiles>CCCC=C(c1ccccc1)N(C)C(=O)OC(F)(F)F</smiles>

370

370<smiles>[R]NC1(c2ccccc2[X])CCCCC1=O</smiles>

280

$\left(\mathrm{M}-\mathrm{COC}_{3} \mathrm{~F}_{7}\right)$

$[\mathrm{M}-188-\mathrm{X}]$

$\left(\mathrm{M}-\mathrm{C}_{9} \mathrm{H}_{7} \mathrm{OF}_{3} \mathrm{X}\right)$<smiles>C=CC=CN(C)C(=O)C(F)(F)C(F)(F)F</smiles>

210<smiles>[X]c1ccccc1C=CC</smiles>

152<smiles>[X]c1ccccc1[CH2-]</smiles>

169

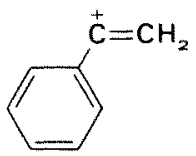

102

$\left[\mathrm{C}_{8} \mathrm{H}_{6}\right]^{+}$

69

69

${ }^{\mathrm{a}} \mathrm{X}=\mathrm{Cl}(1) ; \mathrm{X}=\mathrm{Br}(2)$.

The present g.c.m.s. assays were compared with the g.c. electron capture (g.c.e.c.) assay of Chang and Glazko. ${ }^{2}$ Our results are in complete agreement. However, a problem arises when dealing with a limited volume of plasma with an unknown amount of
$(M-35)^{+}$

$(\mathrm{M}-\mathrm{Cl})$

$[\mathrm{M}-105]^{+}$
$\left(\mathrm{M}-\mathrm{C}_{4} \mathrm{H}_{6} \mathrm{OCI}\right)$

Table 2. Postulated structures of e.i. mass fragments of ketamine metabolite $1 \mathrm{a}$ and ketamine metabolite $1 \mathrm{~b}$

$\begin{array}{cc}\text { la } \mathrm{HFB} & \mathbf{1 b} \mathrm{HFB} \\ \mathrm{m} / \mathrm{e} & \mathrm{m} / \mathrm{e}\end{array}$

$[\mathrm{M}]+$

$419 \quad 417$

$[\mathrm{M}+2]^{+}$

(not shown in spectrum)

421 419

(not shown in spectrum)

362

$[\mathrm{M}-79]^{+}$

$\left(\mathrm{M}-\mathrm{C}_{2} \mathrm{H}_{4} \mathrm{O}-\mathrm{Cl}\right)$<smiles>O=C(NC1(c2ccccc2)CCCCC1=O)C(F)(F)F</smiles>

384

382

$(\mathrm{M}-\mathrm{CO}-\mathrm{Cl})$<smiles>CCC/C=C(\NC(=O)C(F)(F)F)c1ccccc1</smiles>

356

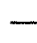

236

$\left[\mathrm{C}_{11} \mathrm{H}_{11}\right]^{+}$<smiles>C=C/C=C(\NC(=O)C(F)(F)C(F)(F)F)c1ccccc1</smiles>

340<smiles>C=C(NC(=O)C(F)(F)C(F)(F)C(F)(F)F)c1ccccc1</smiles>

$\left[\mathrm{C}_{9} \mathrm{H}_{7}\right]^{+}$

$\left[\mathrm{C}_{8} \mathrm{H}_{6}\right]$ t<smiles>C/C=C\C=C/c1ccccc1</smiles>

143<smiles>C=Cc1ccccc1C=CC</smiles>

115

115

102

102

$\left[\mathrm{CF}_{3}\right]^{+}$

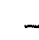

69

-

68

ketamine. Under these circumstances it may not be possible to add the correct amount of internal standard to obtained reasonable proportional peak heights. Disproportionate peaks are more difficult to analyze with g.c.e.c. without a computer, in contrast to the use of a computer capable of normalizing the data. The specificity of g.c.m.s. in both the e.i. and especially the c.i. modes remains a distinct advantage, especially when sample amounts are limited. As shown in the figures, g.c.m.s. sensitivity was quite good but not much better than that achieved by g.c.e.c. The use of g.c.e.c. for routine plasma analysis is adequate but the present g.c.m.s. (e.i. and 


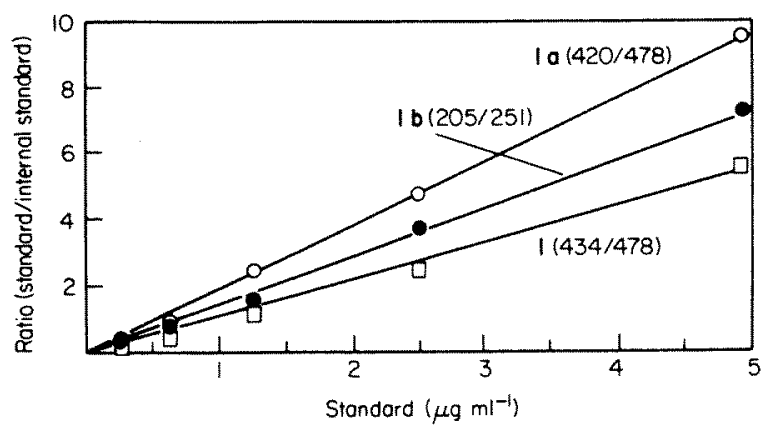

Figure 6. Standard calibration curve for $1,1 \mathrm{a}$ and $1 \mathrm{~b}$ in monkey plasma using chemical ionization (methane) selected ion recording. Variable amounts of $1,1 \mathrm{a}$ and $1 \mathrm{~b}$ and $5 \mu \mathrm{g} \mathrm{ml}^{-1}$ of internal standard were added to monkey plasma as in Fig. 5 . Methane was the reactant gas with a pressure of $380 \mu$. The $y$-axis represents the ratio of areas of the monitored fragments. The $x$-axis represents the amount of drug added to monkey plasma which was extracted and derivatized. The final volume of extracted ethyl acetate was $50 \mu \mathrm{l}$, of which $1 \mu \mathrm{l}$ was injected. Hence, $1 / 50$ of the total amount was analyzed. Note that $5 \mathrm{ng}$ can easily be detected. About $0.5 \mathrm{ng}$ is the limit of sensitivity.

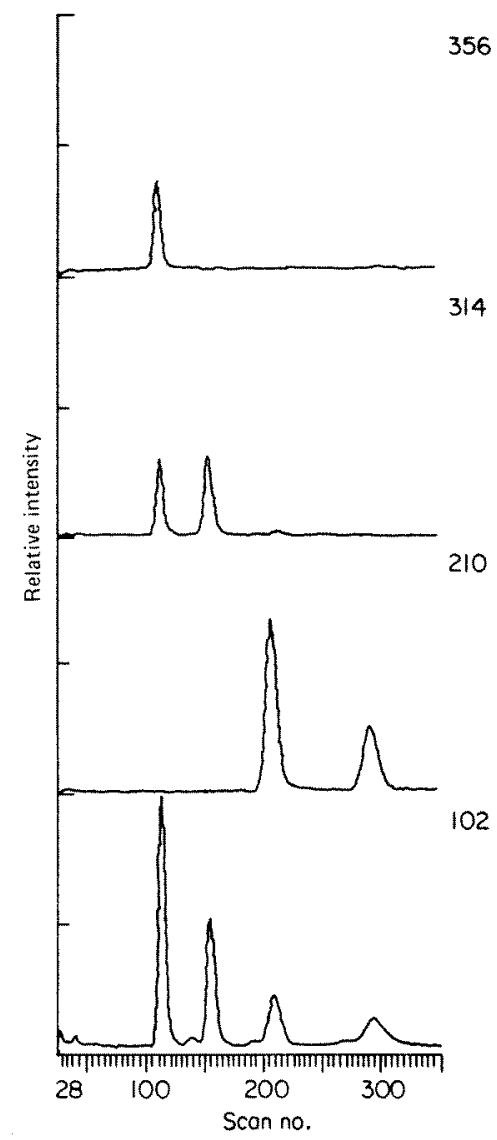

Figure 7. Mass fragmentogram of 1, $1 \mathrm{a}$ and $1 \mathrm{~b}$ extracted from monkey plasma using e.i. The $\mathrm{o}-\mathrm{Br}$ analog of ketamine was added to monkey plasma in a concentration of $3 \mu \mathrm{g} \mathrm{ml}^{-1}$ while ketamine and its metabolites were added in a concentration of $5 \mu \mathrm{g} \mathrm{ml}^{-1}$. One $\mu \mathrm{l}$ of the extracted and derivatized sample $(20 \mu \mathrm{l}$ total volume) was injected. hence, 150 and $250 \mathrm{ng}$ total were analyzed at the a.m.u. noted. Although the quantitative data were obtained from $\mathrm{m} / \mathrm{e} 102$ and 210 , the two metabolites of ketamine were also monitored at $m / e 314$ and 356 for further identification.

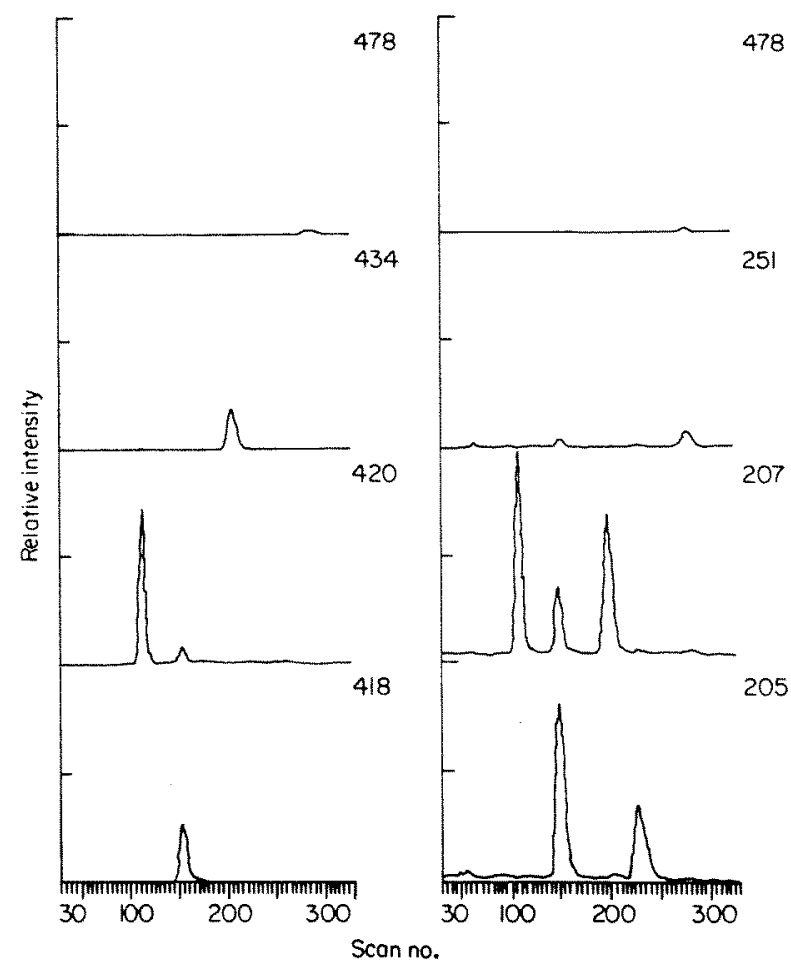

Figure 8. Mass framentogram of 1, 1a and $1 \mathrm{~b}$ extracted from monkey plasma using methane c.i. All compounds were added to monkey plasma in a concentration of $5 \mu \mathrm{g} \mathrm{ml}^{-1}$, extracted and derivatized. One $\mu$ l of the extracted and derivatized sample $(50 \mu \mathrm{l}$ total volume) was injected. Hence, $100 \mathrm{ng}$ of each were injected. The $[\mathrm{M}+\mathrm{H}]^{+}$ions $\mathrm{m} / \mathrm{e} 418,420,434,478$ as well as the ion fragments $m / e 205,207$ and 250 were monitored. For quantitative data ion fragments $m / e \quad 205,251,420,434$ and 478 were used.

especially c.i.) method will prove more useful where specificity is essential. One of the disadvantages of the g.c.e.c. assay is the elaborate extraction and derivatization outlined in Fig. 1. This was used for our g.c.m.s. assays too. One might save considerable time by trying an on-column or precolumn derivatization using heptafluorobutyric anhydride for direct g.c.m.s. com. analysis of the separated products. This might be preferable to the rather involved sample procedure we have used. However, our assay is quite satisfactory as described, for the samples are relatively quite clean.

We would like to stress that the postulated ion structures in Tables 1 and 2 are not supported by high resolution, metastable, or stable isotope incorporation experiments and are to be taken as only a first approximation pending future research.

The authors would like to thank Mr Michael Lutz and Ms Germaine Gwynn for their valuable assistance in the g.c.m.s. assays and $\mathrm{Mr}$ Chang and Drs Glazko, McCarthy and McLean of the Parke Davis and Company Medical Research Laboratories, Ann Arbor, Michigan 48106 for their advice and drug samples, and Dr V Zannoni for his helpful suggestions in preparation of the manuscript.

\section{REFERENCES}

1. W. A. Dill, L. Chucot, T. Chang and A. Glazko, Anesthesiology 34, 73 (1971).

2. T. Chang and A. Glazko, Anesthesiology 36, 401 (1972).

3. J. Wieber, R. Gugier, J. H. Hengstmann and H. J. Dengler, Anaesthetist 24, 260 (1975).

4. M. Cohen, S. Chan, W. Way and A. Trevor, Anesthesiology 39, 370 (1973).
5. T. Chang, A. Savory, M. Albin, R. Goulet and A. Glazko, Clin. Res. 18, 597 (1970).

6. T. Chang, W. A. Dill and A. Glazko, Fed. Proc. 24, 268 (1965).

Received 9 November 1976

(C) Heyden \& Son Ltd, 1977 